\title{
Impact of farmers' practices and seed systems on the genetic structure of common sorghum varieties in Kenya and Sudan
}

\author{
Ismail Y. Rabbi ${ }^{*}$, Hartwig H. Geiger ${ }^{1}$, Bettina I. G. Haussmann ${ }^{1,2}$, \\ Dan Kiambi ${ }^{3}$, Rolf Folkertsma ${ }^{3+}$ and Heiko K. Parzies ${ }^{1}$ \\ ${ }^{1}$ Institute of Plant Breeding, Seed Science, and Population Genetics, \\ University of Hohenheim, 70593 Stuttgart, Germany, ${ }^{2}$ ICRISAT Box 320, Bamako, \\ Mali and ${ }^{3}$ Eastern and Southern Africa International Crops Research Institute for the \\ Semi-Arid Tropics (ICRISAT), PO Box 39063-00623, Nairobi, Kenya
}

Received 10 November 2009; Accepted 13 January 2010 - First published online 5 February 2010

\begin{abstract}
To understand the effect of different farming systems on the dynamics of diversity of sorghum (Sorghum bicolor (L.) Moench) crop, genetic structure of widely used landraces and modern varieties collected from two contrasting agroecosystems, in eastern Sudan and western Kenya, were analysed with 16 polymorphic microsatellite markers. A total of 1104 accessions, grouped into 46 samples from individual farmers, were genotyped. Cluster analysis of the samples from the two countries displayed contrasting patterns. Most strikingly, differently named landraces from western Kenya formed widely overlapping clusters, indicating weak genetic differentiation, while those from eastern Sudan formed clearly distinguishable groups. Similarly, samples of the modern variety from Sudan displayed high homogeneity, whereas the most common modern variety from western Kenya was very heterogeneous. The high degree of fragmentation of farmlands of western Kenya, coupled with planting of different sorghum varieties in the same fields, increases the likelihood of inter-variety gene flow. This may explain the low genetic differentiation between the differently named landraces and heterogeneity of the modern variety from western Kenya. This study highlights the important role of farmers in shaping the genetic variation of their crops and provides population parameter estimates allowing forecasting of the fate of 'modern' germplasm (conventional or genetically modified) when introduced into subsistence farming systems.
\end{abstract}

Keywords: farmers' practices; genetic structure; microsatellites; seed systems; sorghum varieties

\section{Introduction}

Genetic structure of traditional crops such as sorghum (Sorghum bicolor (L.) Moench) grown under traditional farming systems may reflect the interaction between

*Corresponding author. E-mail: irabbi2@yahoo.com

${ }^{+}$Current address: De Ruiter Seeds R\&D NL B.V, PO Box 1050, 2660

BB Bergschenhoek, The Netherlands. evolutionary factors (e.g. mutation, drift, selection and migration) and farmers' practices (Alvarez et al., 2005). Selection and drift promote genetic diversification between populations, while migration, through pollen and seeds, counteracts this effect. Mixed planting of different populations within the same field, a widespread practice in traditional farming systems (Barnaud et al., 2007, 2008), is expected to increase inter-population gene flow. Furthermore, farmers' seed exchange practices seem to be the major cause of long-distance gene flow in cultivated populations (vom Brocke et al., 2003; Parzies et al., 2004). 
The populations of crops that are cultivated by farmers can be grouped into two categories: (1) landraces, formally defined as 'autochthonous varieties with a high capacity to tolerate biotic and abiotic stress, resulting in high yield stability and an intermediate yield level under a low input agricultural system' (Zeven, 1998); (2) modern varieties, which are products of modern plant breeding. In this paper, the term variety is used to denote both landraces and modern varieties when being referred together.

Detailed knowledge of the impact of farmers' practices on the genetic structure of sorghum is required for in situ conservation of genetic resources. In addition, such knowledge is crucial for various reasons. In the absence of a formal seed multiplication system, maintenance of genetic purity of modern varieties largely depends on farmers who traditionally rely on farm-saved seeds (Almekinders et al., 1994). Thus, examining the genetic structure of in situ collected varieties is expected to reveal the likely fate of modern varieties when these are introduced into traditional farming systems. Likewise, such information will be useful for predicting the impact of genetically modified (GM) crops under farmers' management. Despite the potential benefits of GM crops, there is also concern over the possible environmental and agronomic impacts if the transgenes 'escape' and become established in natural or agricultural ecosystems (Ellstrand, 2001; Gepts and Papa, 2003; Snow, 2003). The potential weediness or invasiveness in the crop or in its wild or weedy relatives as a result of introgression of fitness-enhancing abiotic and biotic traits conferred by transgenes, including resistance to herbicides, insects and disease, and drought tolerance (Warwick et al., 2009), is a major ecological concern. So far, natural hybridization has been reported in crop/wild ancestor complex in 22 of the world's most important crop species, including sorghum (Ellstrand et al., 1999; Ellstrand, 2003). The promiscuity of sorghum with its congeners is apparent from the numerous studies which show genetic and/or morphological evidence of crop-to-wild gene flow, especially where the interfertile wild and cultivated sorghums grow sympatrically (Doggett, 1988; Aldrich and Doebley, 1992; Morrell et al., 2005; Barnaud et al., 2009). Understanding farmers' practices is necessary to complement ecological studies (e.g. on pollen dispersal and outcrossing rates), if we are to assess the ecological risk of growing transgenic plants. The impact of formal seed systems may also be discerned from the genetic structure of modern varieties that are commonly planted by the farmers.

The few studies of genetic diversity patterns of sorghum samples collected in situ in 'traditional' farming systems reveal a weak regional differentiation (Djè et al., 1999) and a lack of correlation between environmental factors and diversity patterns (Ayana et al., 2000;
Ghebru et al., 2002). Botanical race has been shown to be the main genetic stratifying factor in sorghum landraces from across Niger (Deu et al., 2008) followed by geographical distribution. In a localized study of the genetic structure of sorghum landraces from a single village in Cameroon, Barnaud et al. (2007) found a substantial and significant differentiation among landraces that are commonly mix-planted. These authors suggested that historical factors, differences in mating system and farmers' practices played significant roles in shaping the genetic structure of the studied landraces. In a follow-up study, Barnaud et al. (2008) found that high outcrossing rates could explain the low genetic differentiation among some landraces, while cleistogamy and pollen competition could explain the significant differentiation of other landraces. The present work is intended to complement and build upon the findings of the previous studies by simultaneous analyses of the genetic structure of sorghum landraces, as well as of that of widely adopted modern varieties, in two countries.

The objectives of this study were: (1) to characterize genetic structure of the most popular sorghum varieties from two different agroecosystems, the Lake Victoria basin region of western Kenya and eastern Sudan, using simple sequence repeats (SSRs); (2) to relate the results on genetic structure to agricultural practices of the farmers, particularly concerning the size of their land holdings, the number of varieties they plant, the presence or absence of isolation practices and their seed systems; (3) to derive recommendations concerning the deployment of improved varieties and of transgenic crops in the study areas, with regard to the maintenance of varietal integrity (particularly that of modern varieties) and the ecological risks of GM gene spread, respectively.

\section{Materials and methods}

\section{Study regions}

Field survey and sample collection were carried out in conjunction with Kenya Agricultural Research Institute in Kenya and Agricultural Research and Technology Corporation (ARTC) in Sudan. Kenya produced about 147,365 metric tons (MT) of sorghum in 2007, of which about $70 \%$ was produced in western Kenya, where land fragmentation is high and average field size is $<0.5$ ha (Ngugi et al., 2002). Most farmers in western Kenya cultivate landraces and use farm-saved seeds. Still, our field survey indicated that an estimated 15\% of these farmers plant modern varieties.

Sudan is the fourth highest producer of sorghum in the world, with about 5,840,000 MT in 2007 
(FAOSTAT, 2009). Eastern Sudan is considered as the main 'breadbasket' of the country. Small-scale subsistence farmers have land holdings of $2-5$ ha (Ayoub, 1999). In addition, large-scale, mechanized farming is mainly practised in the clay plains of eastern Sudan, particularly in Gadaref and in Damazin, with land holdings of 420 ha or larger. Modern varieties are widely adopted in irrigated areas of Sudan.

\section{Plant material}

In December 2006, we collected seed samples of sorghum varieties ( $n=49$ and 45$)$ from farmer households in eastern Sudan and western Kenya, respectively (Fig. 1). Each farmer was asked to provide seed samples of all the varieties that they cultivated. Sampling locations were ascertained using global positioning system co-ordinates. Of these, a subset of 23 samples per country was selected for genotyping (Supplementary Table S1, available online only at http://journals.cambridge.org). Information on farming practices was collected in the form of questionnaire interviews. Specifically, farmers were asked about their field sizes, source of seeds, number and names of varieties cultivated and whether they practised varietal isolation. The most common modern varieties and landraces from both the countries were used for molecular marker analyses. In order to minimize chances of multiple sampling of the same plant, seeds were collected from at least 30 different individual plants per field or from what farmers had stored aside as planting material for the next season.

\section{DNA extraction and SSR genotyping}

DNA was isolated from 24 individual seedlings per sample. Seeds were set to germinate in the laboratory
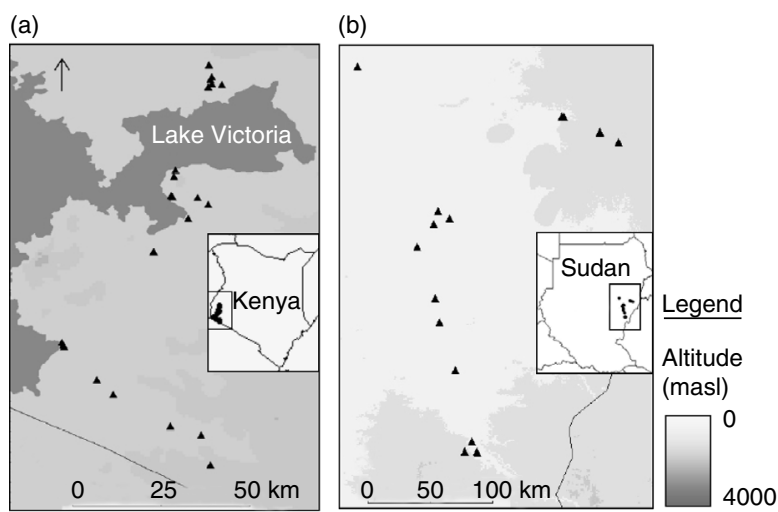

Fig. 1. Sampling locations in (a) Kenya and (b) Sudan. at room temperature using normal garden soil, and DNA was extracted from an approximately 5-cm long piece of leaf tissue of 2-week-old individual seedlings using a modified CTAB protocol (Mace et al., 2003). Concentration and quality of the DNA were assessed using a Nanodrop $1000^{\circledR}$ spectrophotometer and electrophoresis of $1 \mu \mathrm{l}$ on $0.7 \%$ agarose gel followed by normalization of the concentration at $25 \mathrm{ng} / \mu \mathrm{l}$.

A set of 16 sorghum SSR markers was used for genotyping (Table 1). They were developed and characterized by Brown et al. (1996) and Taramino et al. (1997) - Sb series; Schloss et al. (2002) - Xcup series; and Bhattramaki et al. (2000) and Menz et al. (2002) - Xtxp series. Forward primers were labelled with FAM, HEX, NED Or PET, allowing post-PCR pooling of the 16 primer products into four groups. High-throughput PCR in $10-\mu l$ reaction volume was carried out as described by Folkertsma et al. (2005b). Between 0.5 and $1 \mu \mathrm{l}$ of PCR products of the differently labelled primers were multiplexed in $7 \mu \mathrm{l}$ of $\mathrm{HiDi}^{\mathrm{TM}}$ formamide and ROX-labelled GeneScan-500 LIZ $^{\mathrm{TM}}$, size standard $(0.012 \mu \mathrm{l})$ solution. Amplified DNA fragments were denatured and size-fractioned using capillary electrophoresis on an ABI Prism 3730 genetic analyzer automatic DNA sequencer (PE-Applied Biosystems, Foster City, CA, United States). Fragment sizes were determined based on migration relative to the internal size standard using GENEMAPPER version 3.0 software (ABI). The standard genotype 'BTX 623' was run together with the samples on each sample plate to confirm reproducibility of allele sizing.

\section{Data analyses}

\section{Diversity statistics}

All SSR markers showed high reproducibility and were included in the analysis. Standard diversity statistics of mean number of alleles per locus $(A)$; gene diversity $(D)$, also referred to as expected heterozygosity; and polymorphism information content (PIC) were computed. All statistics were calculated using PowerMarker software (Liu and Muse, 2005). Gene diversity at the $l$ th locus was computed as (Weir, 1996):

$$
D_{l}=\frac{1-\sum_{i=1}^{k} p_{i}}{1-\left(1-F_{\mathrm{IS}} / n\right)},
$$

where $P_{i}$ is the frequency of allele $i$ and $F_{\text {IS }}$ is the population inbreeding coefficient.

The PIC of the $l$ th locus, which is closely related to $D_{l}$, provides an estimate of the discriminatory power of a locus, and it was estimated according to 
Table 1. Linkage group (LG), type, number of alleles $(A)$ and polymorphic information content (PIC) of the simple sequence repeat markers in the Sudanese, Kenyan and combined set of samples

\begin{tabular}{|c|c|c|c|c|c|c|c|c|}
\hline \multirow[b]{2}{*}{ Marker } & \multirow[b]{2}{*}{$\mathrm{LG}^{\mathrm{a}}$} & \multirow[b]{2}{*}{ Type $^{b}$} & \multicolumn{2}{|c|}{ Eastern Sudan } & \multicolumn{2}{|c|}{ Western Kenya } & \multicolumn{2}{|c|}{ Pooled samples } \\
\hline & & & $A$ & PIC & $A$ & $\mathrm{PIC}$ & $A$ & $\mathrm{PIC}$ \\
\hline Хсир 02 & $\mathrm{~F}$ & EST & 7 & 0.70 & 4 & 0.09 & 8 & 0.67 \\
\hline Хсup 07 & G & EST & 7 & 0.63 & 5 & 0.54 & 9 & 0.67 \\
\hline Хсир 14 & C & EST & 7 & 0.52 & 3 & 0.50 & 7 & 0.69 \\
\hline Хсир 53 & A & EST & 4 & 0.46 & 3 & 0.14 & 4 & 0.33 \\
\hline Хсир 61 & C & EST & 4 & 0.57 & 2 & 0.24 & 4 & 0.46 \\
\hline Хсир 62 & A & EST & 2 & 0.12 & 2 & 0.21 & 2 & 0.17 \\
\hline Хсир 63 & B & EST & 6 & 0.60 & 4 & 0.09 & 8 & 0.44 \\
\hline Gpsb 089 & A & Genomic & 5 & 0.47 & 5 & 0.31 & 6 & 0.62 \\
\hline Gpsb 114 & G & Genomic & 8 & 0.36 & 8 & 0.54 & 11 & 0.60 \\
\hline IS-10328 & I & Genomic & 7 & 0.57 & 7 & 0.47 & 10 & 0.65 \\
\hline$K A F 1$ & J & Genomic & 5 & 0.40 & 3 & 0.35 & 6 & 0.58 \\
\hline Sb5-206 & $\mathrm{F}$ & Genomic & 14 & 0.28 & 17 & 0.88 & 27 & 0.76 \\
\hline Xtxp 287 & $\mathrm{~F}$ & Genomic & 15 & 0.46 & 11 & 0.72 & 16 & 0.71 \\
\hline Xtxp 304 & B & Genomic & 17 & 0.71 & 14 & 0.58 & 23 & 0.79 \\
\hline Xtxp 320 & A & Genomic & 11 & 0.60 & 7 & 0.57 & 12 & 0.71 \\
\hline Xtxp 321 & $\mathrm{H}$ & Genomic & 22 & 0.73 & 16 & 0.86 & 32 & 0.88 \\
\hline Mean & & & 8.8 & 0.51 & 6.9 & 0.44 & 11.6 & 0.61 \\
\hline SD & & & 1.3 & 0.04 & 1.2 & 0.06 & 2.1 & 0.04 \\
\hline
\end{tabular}

Standard deviation estimated by 10,000 bootstraps.

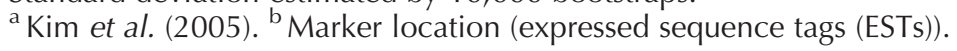

Botstein et al. (1980):

$$
\mathrm{PIC}_{l}=1-\sum_{i=1}^{k} p_{i}^{2}-\sum_{i=1}^{k} \sum_{j=i+1}^{k} 2 p_{i}^{2} p_{j}^{2}
$$

where $P_{i}$ and $P_{j}$ are the frequencies of alleles $i$ and $j$, respectively. Furthermore, allelic richness $\left(A_{\mathrm{e}}\right)$, a measure of the number of alleles independent of sample size, was calculated for each variety (since the sample sizes were different). This was implemented in the software FSTAT (Goudet, 1995).

\section{Analysis of population structure}

Pattern of genetic structure was assessed by three complementary approaches: a Bayesian clustering method; principal co-ordinate analysis ( $\mathrm{PCOA}$ ); and analysis of molecular variance (AMOVA). We used the Bayesian clustering method implemented in the software STRUCTURE 2.2 (Pritchard et al., 2000), which places individual genotypes in $K$ clusters that have distinct marker frequencies, with $K$ being chosen in advance. We used the basic admixture model with uncorrelated allele frequencies, and varied $K$ from 1 to 10 with at least five replicates per $K$, a burning period length of $10^{5}$ iterations, and $10^{5}$ iterations for the post-burning Markov chain convergence. The most appropriate number of clusters $(K)$ was selected employing the method of Evanno et al. (2005), which is based upon an ad hoc quantity $(\Delta K)$ that evaluates a second-order rate of change. Since strongly linked loci lead to spurious clustering (Kaeuffer et al., 2007), only loci that were more than $10 \mathrm{cM}$ apart were used in this study.

A PCoA, which summarizes the variance of multivariate datasets into trends of maximum relevance known as principal components (PCs), was computed from a matrix of pair-wise genetic dissimilarities (measured as 1 - proportion of shared alleles) between individuals calculated by the software DARwin5 (Perrier et al., 2003). For the STRUCTURE analysis and PCoA, we made three assumptions:

(1) If farmers are acquiring seed samples of a particular modern variety from a formal system, then these seed samples should have a high level of homogeneity and form a distinct cluster.

(2) A landrace is more heterogeneous than a modern variety. Yet, seed samples of different landraces may form distinct clusters in the absence of gene flow between them.

(3) Extensive seed exchange between farmers or strong pollen migration among neighbouring varieties prevents clustering of seed samples.

A three-tier nested AMOVA was conducted to quantify the distribution of genetic variation between the countries, among varieties within countries and within varieties, using Arlequin 2.0 (Excoffier et al., 2005). Samples showing 
intermediate ancestry as portrayed by STRUCTURE were excluded from this analysis.

Spatial pattern of genetic structure was assessed by isolation by distance (IBD) software. Values for pairwise genetic differentiation $\left(F_{\mathrm{ST}}\right)$ were regressed on the logarithm of geographical distance between populations. The Mantel test was used to test the independence of matrices using IBD software (Bohonak, 2002).

\section{Results}

\section{Occurrence of varieties}

According to the interviews, farmers in the study area of eastern Sudan planted 11 varieties, with the modern varieties of Wad-Ahmad and Tabat accounting for 19 and $7 \%$ of the collected samples, respectively. The most common landraces were Arfa-Gadamak, Karakola and
Gadam-el-Hamam representing 23, 10 and 8\% of the collected samples, respectively. The remaining varieties ranged from 1 to $6 \%$. On average, individual farmers cultivated 2.5 (range 1-4) varieties in Sudan. The eastern Sudanese farmers usually had large acreages, and most of them practised varietal isolation. Some of these farmers mentioned farm sizes of up to 1050 ha, while the largest field size mentioned in western Kenya was only 10 ha, and the majorities were 1 ha or less (Supplementary Table S1, available online only at http://journals. cambridge.org). Most farmers in western Kenya cultivated landraces, and farm-saved seeds were found to be the major source of planting material in this region. On average, two varieties were grown per farmer's field (range 1-5). About $37 \%$ of these farmers grew only one variety. Eight varieties were frequently mentioned by farmers in western Kenya. Of the samples collected from these farmers, $20 \%$ were Ochuti, while Gopari and Andiwo accounted for 18 and 10\%, respectively.

Table 2. Mean number of alleles per locus $(A)$ and gene diversity $(D)$ of individual and pooled sorghum samples from western Kenya and eastern Sudan based on 16 SSR markers

\begin{tabular}{|c|c|c|c|c|c|c|c|}
\hline & Sudan & & & & Kenya & & \\
\hline $\begin{array}{l}\text { Individual sample } \\
\text { identities }^{\mathrm{a}}\end{array}$ & Local name $^{b}$ & A & $D$ & $\begin{array}{c}\text { Individual sample } \\
\text { identities }\end{array}$ & Local name ${ }^{b}$ & A & $D$ \\
\hline 1 & $\mathrm{AG}^{\mathrm{C}}$ & 2.38 & 0.28 & 1 & $\mathrm{GO}^{\mathrm{c}}$ & 2.63 & 0.27 \\
\hline 2 & AG & 2.75 & 0.26 & 2 & GO & 2.69 & 0.34 \\
\hline 3 & AG & 1.56 & 0.10 & 3 & GO & 2.38 & 0.25 \\
\hline 4 & AG & 2.63 & 0.26 & 4 & $\mathrm{GO}$ & 2.38 & 0.26 \\
\hline 5 & AG & 2.81 & 0.24 & 5 & AND & 2.63 & 0.25 \\
\hline 6 & AG & 2.44 & 0.16 & 6 & AND & 3.06 & 0.33 \\
\hline 7 & AG & 3.06 & 0.26 & 7 & AND & 2.19 & 0.23 \\
\hline 8 & AG & 2.69 & 0.29 & 8 & AND & 2.56 & 0.38 \\
\hline 9 & KK & 2.44 & 0.29 & 9 & AND & 2.19 & 0.17 \\
\hline 10 & KK & 2.75 & 0.25 & 10 & $\mathrm{OCH}$ & 2.81 & 0.29 \\
\hline 11 & KK & 1.75 & 0.22 & 11 & $\mathrm{OCH}$ & 2.94 & 0.35 \\
\hline 12 & KK & 2.63 & 0.17 & 12 & $\mathrm{OCH}$ & 1.63 & 0.06 \\
\hline 13 & KK & 3.00 & 0.38 & 13 & $\mathrm{OCH}$ & 1.81 & 0.08 \\
\hline 14 & KK & 1.94 & 0.14 & 14 & $\mathrm{OCH}$ & 1.44 & 0.05 \\
\hline 15 & WA & 1.38 & 0.06 & 15 & $\mathrm{OCH}$ & 2.69 & 0.34 \\
\hline 16 & WA & 1.75 & 0.08 & 16 & $\mathrm{OCH}$ & 1.50 & 0.11 \\
\hline 17 & WA & 1.56 & 0.06 & 17 & SER & 1.63 & 0.04 \\
\hline 18 & WA & 1.44 & 0.05 & 18 & SER & 2.75 & 0.25 \\
\hline 19 & WA & 2.06 & 0.16 & 19 & SER & 2.63 & 0.17 \\
\hline 20 & WA & 2.88 & 0.21 & 20 & SER & 1.31 & 0.02 \\
\hline 21 & WA & 2.94 & 0.31 & 21 & SER & 1.44 & 0.06 \\
\hline 22 & WA & 3.31 & 0.41 & 22 & SER-GO & 2.44 & 0.31 \\
\hline 23 & WA & 3.38 & 0.37 & 23 & SER & 1.88 & 0.07 \\
\hline Average & & 2.41 & 0.22 & Average & & 2.24 & 0.20 \\
\hline & $\mathrm{AG}(n=144)^{\mathrm{d}}$ & 4.91 & 0.38 & & $\mathrm{GO}(n=96)^{\mathrm{d}}$ & 3.92 & 0.32 \\
\hline & $\mathrm{KK}(n=144)$ & 4.60 & 0.32 & & AND $(n=120)$ & 4.01 & 0.35 \\
\hline & WA $(n=192)$ & 4.73 & 0.20 & & $\mathrm{OCH}(n=168)$ & 4.50 & 0.41 \\
\hline & - & - & - & & $\operatorname{SER}(n=120)$ & 4.10 & 0.27 \\
\hline
\end{tabular}

\footnotetext{
${ }^{a} n=24$ for all samples. ${ }^{b}$ Cultivar abbreviations: AG, Arfa-Gadamak; GO, Gopari; AND, Andiwo; KK, Karakola; OCH, Ochuti; WA, Wad-Ahmad; SER, Seredo. ' ${ }^{\mathrm{L}}$ Landraces: AG, KK, GO and OCH; modern varieties: WA and SER. ${ }^{\mathrm{d}}$ Allelic richness was calculated in order to compensate for the differences in the sample sizes.
} 
About $15 \%$ of these farmers grew the modern variety Seredo. The frequencies of the remaining four varieties were lower than $8 \%$.

\section{Molecular diversity}

The 16 SSR markers revealed a total of 185 alleles, with an average of 11.6 alleles per locus in the entire dataset (Table 1), and 8.8 (range 2-22) and 6.9 (range 2-17) alleles per locus for the Sudanese and the Kenyan set, respectively. The 16 SSRs showed similar pattern of variation in terms of the number of alleles per locus [Pearson product-moment correlation coefficient $(r)=0.92$; $t=8.21, P<0.01]$. A mean PIC per locus of 0.61 was found for the entire dataset ranging from 0.44 to 0.88 when the relatively conserved expressed sequence tag $($ EST)-derived markers Xcup62 $(\mathrm{PIC}=0.17)$ and Xcup53 $(\mathrm{PIC}=0.33)$ were neglected. The PIC values were not significantly different between the Sudanese and Kenyan datasets ( 0.51 and 0.44 , respectively).

Comparison of the genetic variation within seed samples collected from individual farmers showed no significant differences in the number of alleles per locus $(t=-1.053, P=0.30)$. The respective $A$ values for Sudan and Kenya were 2.41 $(\mathrm{SD}=0.61)$ and $2.24(0.55$; Table 2). Similarly, the respective average gene diversities $(D)$ were 0.22 and 0.20 . However, both the statistics ( $A$ and $D$ ) varied widely among samples within countries. It is worth mentioning that samples with low genetic heterogeneity, particularly Wad-Ahmad samples 15-18, show low levels of allelic diversity compared with those with heterogeneous ancestry (samples 20, 21 and 23).

Diversity analyses of pooled samples revealed minor differences between varieties for allelic richness and gene diversity (Table 2). Highly admixed samples as revealed by STRUCTURE analysis and PCOA were excluded from variety grouping in order to avoid false high diversity estimates resulting from Wahlund's 'isolate breaking' effect (Lowe et al., 2004).

\section{Inter-variety differentiation and genetic structure}

The seven varieties studied formed groupings based on the country of origin (Supplementary Fig. S1, available online only at http://journals.cambridge.org). At the country level, the model-based clustering implemented in the software STRUCTURE indicated that the most appropriate numbers of genetically distinct groups $(K)$ for Kenya and Sudan were 2 and 3, respectively (Fig. 2(a) and (b), respectively). At higher $K$ values, the populations did not show consistent clustering even after multiple runs at the same $K$ level. Populations from Kenya formed only two groups (Fig. 2(b)) consisting of the modern variety Seredo in one cluster and all the landraces in the other. Interestingly, the Kenyan landraces clustered neither by name nor by morphology. Seed admixture was detected between the variety Seredo and the landrace Gopari (sample 10). Populations from Sudan are split into the groups Wad-Ahmad, Karakola and Arfa-Gadamak. A high level of heterogeneous ancestry (i.e. multiple cluster assignments) was detected in populations 7, 8, 9 and 22 at $K=3$, indicating possible gene flow between the respective varieties.

The genetic structure was also studied by PCoA. Traditional two-dimensional scatter plots were used to demonstrate global relationship between the varieties, while box plots were used to demonstrate the fine-scale variation
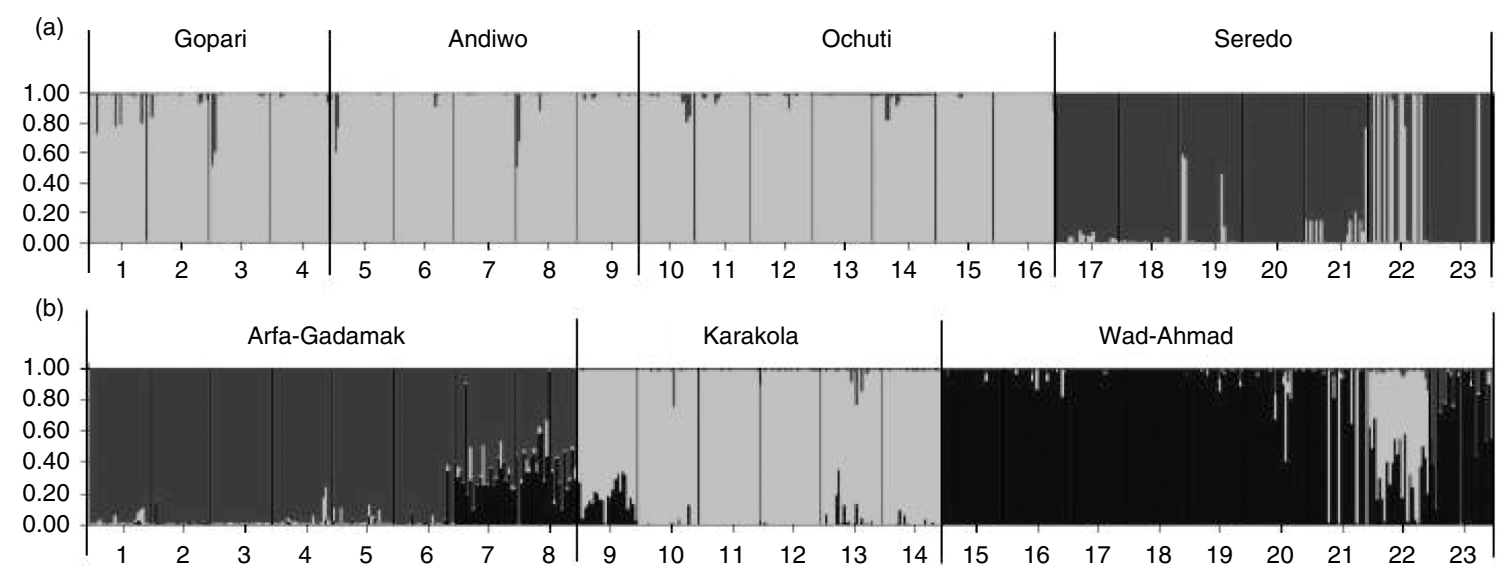

Fig. 2. STRUCTURE analysis of 23 sorghum seeds samples from (a) eastern Sudan and (b) western Kenya genotyped with 16 SSRs. Each vertical line represents an individual. Individuals are clustered by sample number (at bottom), and samples are clustered by variety name (at top). Black and grey represent the inferred ancestry from $K$ populations. 
within and among individual samples. Consistent with the STRUCTURE results, global clustering pattern of PCoA of the Kenyan samples revealed two groups consisting of the modern variety Seredo and the landraces Fig. S2(a), available online only at http://journals. cambridge.org). The first four principal co-ordinates together accounted for $45 \%$ of the extracted variation. Strikingly, the individuals of the modern variety Seredo formed a largely heterogeneous cluster. The differently named Kenyan landraces widely overlapped, indicating insufficient genetic differentiation to resolve them into distinct clusters. Juxtaposition of box plots of the first four PCs, however, indicated subtle differentiations among these landraces (Fig. 3(b)). The second PC distinguished most of the Ochuti samples from those of the other landraces, while PC3 and PC4 only revealed minor differences between Gopari and the other landraces (Fig. 3(a)). Moreover, a high level of genetic heterogeneity was detected among individual samples, particularly within landrace Ochuti and modern variety Seredo. The global clustering pattern of PCoA of the Sudanese sample recapitulated the STRUCTURE results and clearly identified three groups, corresponding to the modern variety Wad-Ahmad and landraces Arfa-Gadamak and Karakola (Supplementary Fig. S2(b), available online only at http://journals.cambridge.org). Individual box plots showed genetic heterogeneity among the individual samples, particularly within the landraces (Fig. 3(a)). The first four co-ordinates (PC1-PC4) together accounted for $53 \%$ of the extracted variation. The samples of the modern variety Wad-Ahmad (15-19) remained largely intact and mapped very closely together. Mixed seed samples (samples 7, 8, 22 and 23) clustered in between their constituent varieties.

Hierarchical AMOVA reiterated the results of STRUCTURE analysis and PCOA, and showed that varieties were mainly structured by the country of origin $(21 \%$; Table 3). Differentiation among varieties accounted for $20 \%$ of the total variation in Sudan, but only for $9 \%$ in Kenya. At the within-variety level, Ochuti from Kenya had the highest level of molecular variance (11\%), while Gopari accounted for $5 \%$ of the total variation.

A Mantel test showed that no significant correlation existed between pair-wise genetic differentiation $\left(F_{\mathrm{ST}}\right)$ and the geographic distance in either of the two countries' samples.

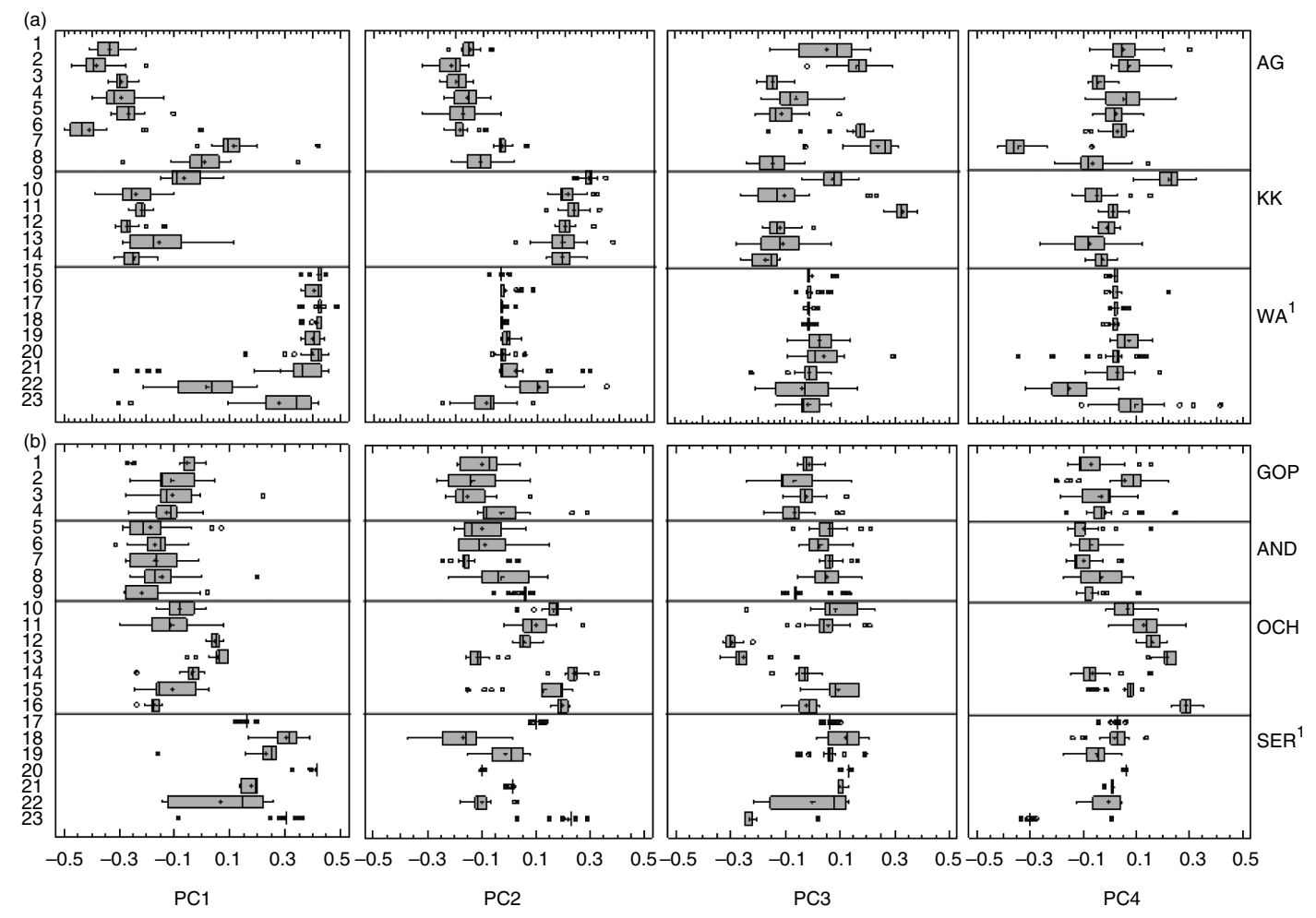

Fig. 3. Box plots of PCoA for the first four principal co-ordinates (PC1-PC4) in (a) Sudanese and (b) Kenyan sorghum samples. Numbers 1-23 represent sample identities. The rectangular part of the plot extends from the lower quartile to the upper quartile of intra-sample variation. The centre lines within each box indicate the medians, whiskers indicate the $95 \%$ confidence interval and plus signs indicate the means. ${ }^{1} \mathrm{AG}$, Arfa-Gadamak; KK, Karakola; WA, Wad-Ahmad; GOP, Gopari; AND, Andiwo; OCH, Ochuti; SER, Seredo. 
Table 3. Analysis of molecular variance with 16 SSRs in the sorghum samples from eastern Sudan and western Kenya

\begin{tabular}{lrrr}
\hline Source of variation $^{\text {a }}$ & d.f. & Sum of square & Variation (\%) \\
\hline Among countries & 1 & 4291.7 & 21.1 \\
Among cultivars within Kenya & 3 & 1840.8 & 9.0 \\
Among cultivars within Sudan & 2 & 4069.8 & 20.0 \\
Within Andiwo & 119 & 1278.4 & 6.7 \\
Within Gopari & 95 & 980.3 & 5.0 \\
Within Ochuti & 167 & 2182.3 & 11.0 \\
Within Seredo & 119 & 983.4 & 5.3 \\
Within Arfa-Gadamak & 143 & 1316.1 & 7.3 \\
Within Karakola & 143 & 1456.3 & 8.7 \\
Within Wad-Ahmad & 191 & 1046.9 & 100.0 \\
Total & 983 & 20366.1 & \\
\hline d.f., Degrees of freedom. & & &
\end{tabular}

\section{Discussion}

\section{Genetic diversity}

The field surveys of our study showed that farmers in both the countries grow a large number of sorghum landraces though no individual farmer grows all the varieties. The estimated average of 8 and 11 varieties in the study regions of western Kenya and eastern Sudan, respectively, is slightly higher than that reported for Niger (6, Deu et al., 2008), but is much smaller than that reported for a single village in northern Cameroon (46, Barnaud et al., 2007). The large number of landraces grown in a restricted region underscores the importance of farmers in conservation of crop genetic resources. Farmers plant multiple varieties to serve their diverse needs, as well as to lower the risk of crop failure owing to biotic and abiotic constraints. In Ethiopia, Teshome et al. (1997) showed an average of 9.75 landraces per field. Barnaud et al. (2007) recorded an average of 12 landraces per field in a single village in Cameroon.

The 16 SSR marker loci used in this study revealed considerable allelic diversity. The level of gene diversity uncovered is similar to that in other SSR-based studies of in situ collected sorghum in Niger (Deu et al., 2008), Cameroon (Barnaud et al., 2007) and South Africa (Uptmoor et al., 2003), but is slightly lower than the estimates from Morocco reported by Djè et al. (1999) and from Eritrea reported by Ghebru et al. (2002). However, it should be noted that the above-quoted studies encompassed large numbers of varieties, while in the present study, only the most common varieties from western Kenya and eastern Sudan were analysed. Furthermore, direct comparisons of genetic diversity between in situ studies are difficult, since estimates depend on factors such as seed sampling scheme and the number and characteristics of the markers employed (Deu et al., 2008).
For instance, microsatellites derived from ESTs were generally less polymorphic than genomic SSRs. In our study, 7 of the 16 SSR markers were derived from ESTs. On average, the latter had 6 alleles per locus compared with 15.5 for the genomic SSRs. The PIC values found here are similar to the estimates reported by other authors (Smith et al., 2000; Folkertsma et al., 2005b). Due to high PIC values of our markers, their discriminatory power can be considered adequate for the present purpose. The mean intra-sample genetic diversity per locus was similar in both the countries, suggesting that farmers maintain similar levels of on-farm diversity. However, the sample from Sudan had slightly higher overall marker diversity values, which may be attributed to Sudan's location at the centre of diversity of sorghum (Doggett, 1988).

\section{Farmers' practices and genetic structure}

Genetic structure analysed by different approaches (STRUCTURE, PCOA and AMOVA) revealed contrasting patterns in the Kenyan and Sudanese study regions. The clear differentiation among the three most common Sudanese varieties confirmed the results obtained by Abu Assar et al. (2005) with SSR markers. The failure by STRUCTURE, and to a lesser extent by PCoA, to resolve the Kenyan landraces is due to their low degree of differentiation as shown by the AMOVA results. The lack of genetic resolution among these common landraces by the neutral SSR markers may be due to extensive gene flow among them that is abetted by the mixedplanting of different varieties that is widely practised by the majority of farmers in western Kenya. Furthermore, different varieties often grow side by side to form a mosaic pattern even though the farmers plant single varieties due to the highly fragmented agricultural landscape 
of western Kenya with an average field size of less than 0.5 ha. In a parallel study, we found that extensive pollen-mediated gene flow occurs up to $10 \mathrm{~m}$ in sorghum (Rabbi et al., 2010). On the other hand, varietal isolation practised by Sudanese farmers could explain the genetic distinctness among the different varieties. Lack of genetic differentiation among landraces that are commonly mix-planted has been documented by Barnaud et al. (2007) in Cameroon. These landraces were subsequently shown to have a relatively high outcrossing rate of up to 40\% (Barnaud et al., 2008).

The lack of a clear differentiation among the differently named Kenyan landraces (Supplementary Fig. S2, available online only at http://journals.cambridge.org) suggests that they can be considered as a single gene pool. However, the Kenyan landraces are morphologically distinct, despite the weak molecular genetic differentiation observed in our study. For instance, Ochuti plants are mainly red seeded, while Andiwo and Gopari bear light-brown seeds. Conservative selection by farmers for visually assessable traits in sorghum may be responsible for morphological identity despite high gene flow among them. The practice of conservative selection has been documented for sorghum (Alvarez et al., 2005; Barnaud et al., 2007) and maize (Pressoir and Berthaud, 2004).

A closer look at the clustering provided by STRUCTURE (Fig. 2) reveals different degrees of hybridization between certain sorghum varieties in western Kenya and eastern Sudan. In Sudan, hybridization seems to occur between variety Wad-Ahmad and each of the two landraces (Arfa-Gadamak and Karakola), but rarely between the two landraces themselves. This migration pattern may be explained by the fact that the modern variety Wad-Ahmad excels in many farmer-preferred traits, and therefore has a higher chance of being admixed to farmers' landraces. The farmers who provided some of these intermediate samples (7-9 and 23) mentioned that they have been using farm-saved seeds for $4-8$ years. They had probably planted Wad-Ahmad close to or mixed with their preferred landraces for several generations. This means that not all Sudanese farmers practise varietal isolation, and that some have practices similar to those of the western Kenyan farmers.

\section{Impacts of formal and informal seed systems in the observed genetic structure}

Gene flow is expected to decrease with geographic distance. Results of the Mantel test showed a lack of correlation between pair-wise genetic differentiation $\left(F_{\mathrm{ST}}\right)$ and geographical distance, suggesting long-distance exchange of genetic materials between farmers in both
Sudan and Kenya. The directionality of seed exchange is difficult to trace, and merits further investigation. However, the impact of the formal seed sector is easy to detect from the genetic structure of the analysed samples of modern varieties: seeds from the formal sector are expected to show a high level of homogeneity. This is confirmed by the clustering pattern of samples of the Sudanese modern variety Wad-Ahmad (15-20; PCoA; Fig. 3(b)). Farmers who provided these samples mentioned that they had obtained the seeds from the formal seed sector of Sudan (Supplementary Table S1, available online only at http://journals.cambridge.org). In contrast, samples of variety Seredo from western Kenya formed a relatively loose cluster. Indeed, most western Kenyan subsistence farmers do not regularly purchase fresh seeds from the formal seed sector. Furthermore, the Seredo is usually incorporated into the local germplasm and is commonly planted alongside the landraces. This process has previously been documented for maize cultivated in Mexico by subsistence farmers and is referred to as 'creolization' (Bellon and Brush, 1994). Under this process, intensive gene flow occurs between modern varieties and farmers' landraces. Consequently, in the course of time, newly introduced modern varieties will change from a rather uniform structure to a heterogeneous structure.

\section{Implications for maintenance of varietal integrity and deployment of transgenic sorghum}

Farmers' seed management in principle could be used for the distribution of modern varieties. However, maintaining varietal purity is difficult in such a system. In an ongoing research project, farmer-preferred landraces from various African countries are being improved for important traits such as resistance against Striga hermonthica (Folkertsma et al., 2005a) and against drought (Borrel et al., 1999). The future stability of these introgressed traits depends on minimizing intercrossing with non-modern varieties that grow in farmers' diverse fields. Intercrossing would result in recombination and consequently in genetic heterogeneity. According to the results of this study, the risk of compromising genetic purity of modern varieties is greater in western Kenya than under the Sudanese farming system. This risk could even be greater in other regions such as Cameroon and Ethiopia, where about a dozen varieties are grown per farmer's field (Teshome et al., 1997; Barnaud et al., 2007). Though selection based on morphological traits is effective in maintaining identities of particular landraces, it may not be effective for other traits whose phenotypes are not visually discernible. These traits may include quantitative trait loci 
conferring resistance or tolerance to biotic and abiotic constraints. To counteract this risk, a more active involvement of the formal seed sector is needed. In addition, the outcrossing rate of modern varieties needs to be determined, since frequency of pollen-mediated gene flow is primarily determined by pollen load of a donor and outcrossing rates of a pollen recipient (Lu and Yang, 2009). If a newly introduced modern variety has a low outcrossing rate, farmers can re-plant it for several seasons without much deterioration of genetic integrity.

This study offers a 'preview' on the frequency of potential hybridization between GM and non-GM sorghum under contrasting seed management and farming systems. Like the modern varieties analysed in this study, GM genes are likely to spread more rapidly in the germplasm of western Kenya than in that of eastern Sudan due to lack of spatial isolation between different varieties that are often mix-planted. Nonetheless, this risk also exists in Sudan, since some of the farmers follow practices similar to those of their Kenyan counterparts, and their seed samples documented hybridization between the modern variety Wad-Ahmad and the two landraces studied.

\section{Acknowledgements}

This research was funded by Bundesministerium für Zusammenarbeit, Bonn. The first author was sponsored by Deutscher Akademischer Austauschdienst, and he carried out the study as part of his $\mathrm{PhD}$ thesis. The authors thank Dr Mohamed Abdalla, ARTC, WadMedani, for organizing the field work in Sudan. Laboratory assistance of Baireddy Chiranjeevi Reddy is gratefully acknowledged. The authors thank the reviewers who provided tremendous help through important, accurate and constructive suggestions for improving this manuscript.

\section{References}

Abu Assar AH, Uptmoor R, Abdelmula AA, Salih M, Ordon F and Friedt W (2005) Genetic variation in sorghum germplasm from Sudan ICRISAT and USA assessed by simple sequence repeats (SSRs). Crop Science 45: 1636-1644.

Aldrich PR and Doebley J (1992) Restriction fragment variation in the nuclear and chloroplast genomes of cultivated and wild Sorghum bicolor. Theor. Appl. Genet. 85: 293-302.

Almekinders CJM, Louwaars NP and de Bruin GH (1994) Local seed systems and their importance for an modern seed supply in developing countries. Euphytica 78: 207-216.

Alvarez N, Garine E, Khasah C, Dounias E, Hossaert-McKey M and McKey D (2005) Farmers' practices, metapopulation dynamics, and conservation of agricultural biodiversity on-farm: a case study of sorghum among the Duupa in sub-Sahelian Cameroon. Biological Conservation 121: $533-543$.

Ayana A, Bryngelsson T and Bekele E (2000) Genetic variation of Ethiopian and Eritrean sorghum (Sorghum bicolor (L.) Moench) germplasm assessed by random amplified polymorphic DNA (RAPD). Genetic Resources and Crop Evolution 47: 471-482.

Ayoub AT (1999) Land degradation, rainfall variability and food production in the Sahelian zone of the Sudan. Land Degradation and Development 10: 489-500.

Barnaud A, Deu M, Garine E, McKey D and Joly HI (2007) Local genetic diversity of sorghum in a village in northern Cameroon: structure and dynamics of landraces. Theoretical and Applied Genetics 114: 237-248.

Barnaud A, Trigueros G, McKey D and Joly HI (2008) High outcrossing rates in fields with mixed sorghum landraces: how are landraces maintained? Heredity 101: 445-452.

Barnaud A, Deu M, Garine E, Chantereau J, Bolteu J, Koïda EO, McKey D and Joly HI (2009) A weed-crop complex in sorghum: the dynamics of genetic diversity in a traditional farming system. American Journal of Botany 96: 1869-1879.

Bellon MR and Brush SB (1994) Keepers of maize in Chiapas, Mexico. Economic Botany 48: 196-209.

Bhattramakki D, Dong J, Chhabra AK and Hart GE (2000) An integrated SSR and RFLP linkage map of Sorghum bicolor (L.) Moench. Genome 43: 988-1002.

Bohonak AJ (2002) IBD (isolation by distance): a program for analyses of isolation by distance. Journal of Heredity 93: $153-154$.

Borrell AK, Tao Y and McIntyre CL (1999) Physiological basis, QTL and MAS of the stay-green drought resistance trait in grain sorghum. Available at http://www.cimmyt. org/ABC/map/research_tools_results/WSMolecular/ WorkshopMolecular/WorkshopMolecularcontents.htm (accessed 7 February 2008).

Botstein D, White RL, Skolnick M and Davis RW (1980) Construction of a genetic linkage map in man using restriction fragment length polymorphisms. American Journal of Human Genetics 32: 314-331.

Brown SM, Hopkins MS, Mitchell SE, Senior ML, Wang TY, Duncan RR, Gonzalez Candelas F and Kresovich S (1996) Multiple methods for the identification of polymorphic simple sequence repeats (SSRs) in sorghum (Sorghum bicolor (L.) Moench). Theoretical and Applied Genetics 93: 190-198.

Deu M, Sagnard F, Chantereau J, Calatayud C, Hérault D, Mariac C, Pham J-L, Vigouroux Y, Kapran I, Traore PS, Mamadou A, Gerard B, Ndjeunga J and Bezançon G (2008) Nigerwide assessment of in situ sorghum genetic diversity with microsatellite markers. Theoretical and Applied Genetics 116: 903-913.

Djè Y, Forcioli D, Ater M, Lefèbre C and Vekemans X (1999) Assessing population genetic structure of sorghum landraces from North-Western Morocco using allozyme and microsatellite markers. Theoretical and Applied Genetics 99: $157-163$.

Doggett H (1988) Sorghum. 2nd edn. Essex: Longman.

Ellstrand NC (2001) When transgenes wander, should we worry? Plant Physiology 125: 1543-1545. 
Ellstrand NC (2003) Dangerous liaisons - when cultivated plants mate with their wild relatives. Baltimore, MD/London: Johns Hopkins University Press, p. 244.

Ellstrand NC, Prentice HC and Hancock JF (1999) Gene flow and introgression from domesticated plants into their wild relatives. Annual Review of Ecology and Systematic 30: $539-563$.

Evanno G, Regnaut S and Goudet J (2005) Detecting the number of clusters of individuals using the software STRUCTURE: a simulation study. Molecular Ecology 14: 2611-2620.

Excoffier L, Laval G and Schneider S (2005) Arlequin ver. 30: an integrated software package for population genetics data analysis. Evolutionary Bioinformatics Online 1: $47-50$.

FAOSTAT. Available at http://faostat.fao.org/ (accessed 3 October 2009).

Folkertsma RT, Haussmann BIG, Parzies HK, Hoffmann V and Geiger HH (2005a) Arresting the scourge of Striga on sorghum in Africa by combining the strengths of markerassisted backcrossing and farmer-participatory selection. In: Deutscher Tropentag, October 11-13, 2005, Hohenheim. Available at http://www.tropentag.de/2005/abstracts/links/ Parzies_NfQBcDqx.pdf (accessed 11 May 2009).

Folkertsma RT, Rattunde HFW, Chandra S, Raju GS and Hash CT (2005b) The pattern of genetic diversity of Guinea-race Sorghum bicolor (L.) Moench landraces as revealed with SSR markers. Theoretical and Applied Genetics 111: 399-409.

Gepts P and Papa R (2003) Possible effects of (trans)gene flow from crops on the genetic diversity from landraces and wild relatives. Env Biosafety Res 2: 89-103.

Ghebru B, Schmidt RJ and Bennetzen JL (2002) Genetic diversity of Eritrean sorghum landraces assessed with simple sequence repeat (SSR) markers. Theoretical and Applied Genetics 105: 229-236.

Goudet J (1995) Fstat version 1.2: a computer program to calculate F-statistics. Journal of Heredity 86: 485-486.

Kaeuffer R, Réale D, Coltman DW and Pontier D (2007) Detecting population structure using STRUCTURE software: effect of background linkage disequilibrium. Heredity 99: 374-380.

Kim J-S, Klein PE, Klein RR, Price HJ, Mullet JE and Stelly DM (2005) Chromosome identification and nomenclature of Sorghum bicolor. Genetics 169: 955-965.

Liu K and Muse S (2004) POWERMARKER: new genetic data analysis software version 3. Available at http://www. powermarker.net

Lowe A, Harris S and Ashton P (2004) Ecological genetics: design, analysis and application. 1st edn. Oxford: Blackwell Publishing, p. 60.

Lu B-R and Yang C (2009) Gene flow from genetically modified rice to its wild relatives: assessing potential ecological consequences. Biotechnology Advances 27: 1083-1091.

Mace ES, Buhariwalla HK and Crouch JHA (2003) A high throughput DNA extraction protocol for molecular breeding programs. Plant Molecular Biology Report 21: 459-460.

Menz MA, Klein RR, Mullet JE, Obert JA, Unruh NC and Klein PEA (2002) A high-density genetic map of Sorghum bicolor (L.) Moench based on 2926 AFLP (R), RFLP and SSR markers. Plant Molecular Biology 48: 483-499.

Morrell PL, Williams-Coplin TD, Lattu AL, Bowers JE, Chandler JM and Patterson AH (2005) Crop-to-weed introgression has impacted allelic composition of johnsongrass populations with and without recent exposure to cultivated sorghum. Molecular Ecology 14: 2143-2154.

Ngugi HK, King SB, Abayo GO and Reddy YVR (2002) Prevalence, incidence, and severity of sorghum diseases in western Kenya. Plant Disease 86: 65-70.

Parzies HK, Spoor W and Ennos RA (2004) Inferring seed exchange between farmers from population genetic structure of barley landrace Arabi Aswad from Northern Syria. Genetic Resources and Crop Evolution 51: 471-478.

Perrier X, Flori A and Bonnot F (2003) Data analysis methods. In: Hamon P, Seguin M, Perrier X and Glaszmann JC (eds) Genetic Diversity of Cultivated Tropical Plants. Montpellier: Enfield Science Publishers, pp. 43-76.

Pressoir G and Berthaud J (2004) Population structure and a strong divergent selection shape phenotypic diversification in maize landraces. Heredity 92: 95-101.

Pritchard JK, Stephens M and Donnelly P (2000) Inference of population structure using multilocus genotype data. Genetics 155: 45-59.

Rabbi IY, Parzies HK, Kiambi D, Haussmann BIG, Folkertsma R and Geiger HH (2010) Experimental studies on pollenmediated gene flow in Sorghum bicolor (L.) Moench using male-sterile bait plants. Under review in Plant Breeding.

Schloss SJ, Mitchell SE, White GM, Kukatla R, Bowers JE, Paterson AH and Kresovich S (2002) Characterization of RFLP probe sequences for gene discovery and SSR development in Sorghum bicolor (L.) Moench. Theoretical and Applied Genetics 105: 912-920.

Smith JSC, Kresovich S, Hopkins MS, Mitchell SE, Dean RE, Woodman WL, Lee M and Porter K (2000) Genetic diversity among elite sorghum inbred lines assessed with simple sequence repeats. Crop Science 40: 226-232.

Snow AA (2003) Genetic engineering: unnatural selection. Nature 424: 619.

Taramino G, Tarchini R, Ferrario S, Lee M and Pe ME (1997) Characterization and mapping of simple sequence repeats (SSRs) in Sorghum bicolor. Theoretical and Applied Genetics 95: 66-72.

Teshome A, Baum BR, Fahrig L, Torrance JK, Arnason TJ and Lambert JD (1997) Sorghum [Sorghum bicolor (L.) Moench] landrace variation and classification in North Shewa and South Welo, Ethiopia. Euphytica 97: 255-263.

Uptmoor R, Wenzel W, Friedt W, Donaldson G and Ayisi K (2003) Comparative analysis on the genetic relatedness of Sorghum bicolor accessions from Southern Africa by RAPDs AFLPs and SSRs. Theoretical and Applied Genetics 106: 1316-1325.

vom Brocke K, Christinck A, Welteien R, Presterl T and Geiger HH (2003) Farmers' seed systems and management practices determine pearl millet genetic diversity patterns in semi-arid regions of India. Crop Science 43: 1680-1689.

Warwick SI, Beckie HJ and Hall MLM (2009) Gene flow, invasiveness, and ecological impact of genetically modified crops. Annals of New York Academy of Sciences 1168: 72-99.

Weir BS (1996) Genetic Data Analysis II: Methods for Discrete Population Genetic Data. Sunderland, MA: Sinauer Associates.

Zeven AC (1998) Landraces: a review of definitions and classifications. Euphytica 104: 127-139. 